\title{
Geoprocessamento aplicado à identificação de áreas propícias ao cultivo de café
}

\author{
Geoprocessing applied to the identification of areas suitable for coffee cultivation \\ Geoprocesamiento aplicado a la identificación de áreas aptas para el cultivo de café
}

\author{
Marinaldo Loures Ferreira \\ ORCID: https://orcid.org/0000-0002-8106-2793 \\ Universidade Federal dos Vales do Jequitinhonha e Mucuri, Brasil \\ E-mail: marinaldo79@gmail.com \\ André Medeiros de Andrade \\ ORCID: https://orcid.org/0000-0003-3502-7847 \\ Universidade Federal dos Vales do Jequitinhonha e Mucuri, Brasil \\ E-mail: andre.medeiros@ufvjm.edu.br \\ Wesley Esdras Santiago \\ ORCID: https://orcid.org/0000-0003-1775-5701 \\ Universidade Federal dos Vales do Jequitinhonha e Mucuri, Brasil \\ E-mail: wesley.santiago@ufvjm.edu.br
}

\begin{abstract}
Resumo
O Brasil é o maior produtor de café no mundo, com destaque para Minas Gerais, responsável por aproximadamente $50 \%$ da produção nacional do grão. Para implantação de lavouras de café é preciso um bom planejamento e conhecimento técnico das variáveis ambientais, informações estas, que podem ser obtidas com as técnicas de geoprocessamento, auxiliando nas tomadas de decisões. Este trabalho tem como objetivo mapear as áreas propícias ao cultivo do café da espécie Coffea Arabica L. no município de Caratinga, Minas Gerais. A análise espacial utilizou dados do Mapbiomas, Portal do Café de Minas e IDE-Sisema, informações estas, associadas a aplicações de restrições técnicas e legais, possibilitado pela análise multicritérios do geoprocessamento. O resultado demonstra que Caratinga tem grande potencial para implantação de novas lavouras de café arábica, possuindo 38,3\% do território apto ao cultivo do grão. Conclui-se que os métodos utilizados foram capazes de delimitar as áreas potenciais para o plantio da cultura, evidenciando ser uma importante ferramenta para auxiliar nesse tipo de tomada de decisão.
\end{abstract}

Palavras-chave: Café; Mapeamento; Geoprocessamento.

\begin{abstract}
Brazil is the largest coffee producer in the world, especially in Minas Gerais, responsible for approximately $50 \%$ of the national production of coffee beans. For the implementation of coffee plantations, it is necessary a good planning and technical knowledge of the environmental variables, information that can be obtained with the techniques of geoprocessing, helping in the decision-making. This work aims to map the areas conducive to the cultivation of coffee species Coffea Arabica L. in the municipality of Caratinga, Minas Gerais. The spatial analysis used data from Mapbiomas, Portal do Café de Minas and IDE-Sisema, information associated with applications of technical and legal restrictions, enabled by the multicriterio analysis of geoprocessing. The result shows that Caratinga has great potential for implantation of new arabica coffee plantations, possessing $38.3 \%$ of the territory apt to the grain cultivation. It is concluded that the methods used were able to delimit the potential areas for planting the crop, proving to be an important tool to assist in this type of decision-making.
\end{abstract}

Keywords: Coffee; Mapping; Geoprocessing.

\begin{abstract}
Resumen
Brasil es el mayor productor de café del mundo, especialmente Minas Gerais, responsable de aproximadamente el $50 \%$ de la producción nacional del grano. Para la implantación de cultivos de café es necesaria una buena planificación y conocimiento técnico de las variables ambientales, información que se puede obtener con técnicas de geoprocesamiento, ayudando en la toma de decisiones. Este trabajo tiene como objetivo mapear las áreas aptas para el cultivo de café de la especie Coffea Arabica L. en el municipio de Caratinga, Minas Gerais. El análisis espacial utilizó datos de Mapbiomas, Portal do Café de Minas e IDE-Sisema, información asociada a aplicaciones de restricciones técnicas y legales, posibilitadas por el análisis multicriterio de geoprocesamiento. El resultado demuestra que Caratinga tiene un gran potencial para la implantación de nuevos cultivos de café Arábica, teniendo un 38,3\% del territorio apto para el cultivo del grano. Se concluye que los métodos utilizados permitieron delimitar las áreas potenciales para la siembra del cultivo, demostrando que es una herramienta importante para ayudar en este tipo de toma de decisiones.
\end{abstract}

Palabras clave: Café; Cartografía; Geoprocesamiento. 


\section{Introdução}

O café é o fruto da planta Coffea da família Rubiaceae, natural da Etiópia, no qual se destaca duas espécies importantes e mundialmente cultivadas. Dentre elas a Coffea arabica L. (café arábica) e a Coffea canéfora (café robusta ou conilon), cujo histórico, sua chegada ao Brasil foi no ano 1727, por Belém no Pará, vindo da Guiana Francesa e posteriormente espalhado da Região Norte para vários Estados Brasileiros (MAPA, 2018).

O Brasil é um dos maiores produtores de café no mundo, responsável por 63,08 milhões de sacas de café beneficiada em 2020, sendo 48,77 milhões de sacas da espécie de café arábica, o que representa em torno de 70\% da safra, e 14,31 milhões de sacas da espécie conilon, que correspondem a 30\%. Dentre os estados Brasileiros, Minas Gerais se destaca com a maior produção do grão, com aproximadamente 50\% da produção nacional (CONAB, 2020).

A cafeicultura tem participação ativa no crescimento econômico do país, principalmente nas principais regiões produtoras, como é o caso de Minas Gerais, em que o café se destaca como o principal produto de exportação do agronegócio, sendo um importante gerador de empregos, renda e principalmente, um meio de vida para milhares de agricultores mineiros (Mesquita et al., 2016; Ximenes \& Vidal, 2017).

Minas Gerais tem uma área cultivada de 1,2 milhão de hectares e são divididas em quatro regiões produtoras, dentre elas a macrorregião Norte de Minas (Norte, Vales do Jequitinhonha e Mucuri) com 77 municípios produtores e uma área plantada de 28,7 mil ha. A região do Cerrado Mineiro (Triângulo Mineiro, Alto Paranaíba e Nordeste) possui 51 municípios e uma área cafeeira de 226,5 mil hectares. A região da Zona da Mata mineira (Zona da Mata, Vale do Rio Doce e região Central) soma 181 municípios e uma área cultivada de 323,8 mil hectares e por fim, a região Sul de Minas (Sul e Centro-Oeste), que totaliza 667,2 mil hectares plantados em 154 municípios, sendo a maior região produtora de café do estado (CONAB, 2020; Portal do café de Minas, 2018).

O município de Caratinga tem como uma das principais fontes de renda a cafeicultura, somando 12.342 hectares com cultivo do grão. Situada na região do Vale do Rio Doce e com um relevo predominante de mares de morros e montanhas. Possui altitude média de $726 \mathrm{~m}$, contribuindo de forma significativa para a produtividade de café no ano de 2020 (Portal do café de Minas, 2018; IBGE, 2019).

O planejamento é parte fundamental da administração de um empreendimento e contribuir na tomada de decisões, portanto, para a implantação da lavoura cafeeira, faz-se necessário um estudo minucioso visando atender uma proposta, antes de tudo, econômica e que mantenha as condições de equilíbrio do sistema. Alguns parâmetros são fundamentais para a escolha de locais viáveis para a implantação de lavouras de café. A topografia a exemplo, influencia diretamente na escolha das cultivares, no sistema de plantio, no espaçamento e na mecanização dos tratos culturais e colheita (Mesquita et al., 2016). O solo deve propiciar um ambiente favorável ao pleno desenvolvimento da cultura, portanto suas características físicas, químicas e biológicas interferem para o bom desenvolvimento da planta. A altitude recomendada para o café arábica, espécie predominante em Minas Gerais, varia entre 600 a 1200 m devido a influência que exerce na produtividade da lavoura e na qualidade da bebida (SENAR, 2017).

$\mathrm{Na}$ fase de implantação e formação da lavoura cafeeira, recomenda-se utilizar culturas intercalares no primeiro e segundo ano de formação para diluir e amenizar as despesas com a implantação da cultura (Nasser et al., 2012).

O geoprocessamento através de suas geotecnologias tem se mostrado uma ferramenta indispensável ao estudo, controle e planejamento da agricultura no País (Ferreira et al., 2018; Cobra et al., 2019). Sua aplicação permite a estimativa de safras (Rosa et al., 2010), definição de áreas aptas ao cultivo de determinada cultura (Barros et al., 2019), dentre várias outras aplicações ao meio rural, fornecendo dados técnicos que auxiliam nas tomadas de decisões (Ângelo et al., 2017; Silva \& Medeiros, 2020). 
O presente estudo tem como objetivo o mapeamento de áreas propícias para a implantação de lavouras de café, em especial a espécie Coffea Arabica L. no município de Caratinga, Minas Gerais (MG), observando as recomendações técnicas e ambientais cabíveis.

\section{Metodologia}

\section{1 Área de estudo}

A área estudada corresponde ao município de Caratinga (Figura 1), localizado no Leste de Minas Gerais, com $1.258,479 \mathrm{~km}^{2}$ de unidade territorial e população estimada de 92.062 habitantes (IBGE, 2019). O clima é tropical ameno com temperatura média de $22,1^{\circ} \mathrm{C}$ e pluviosidade média anual de $1.150 \mathrm{~mm}$ (INMET, 2019).

Figura 1 - Mapa de localização. A) Município de Caratinga em Minas Gerais. B) Limite de Caratinga.

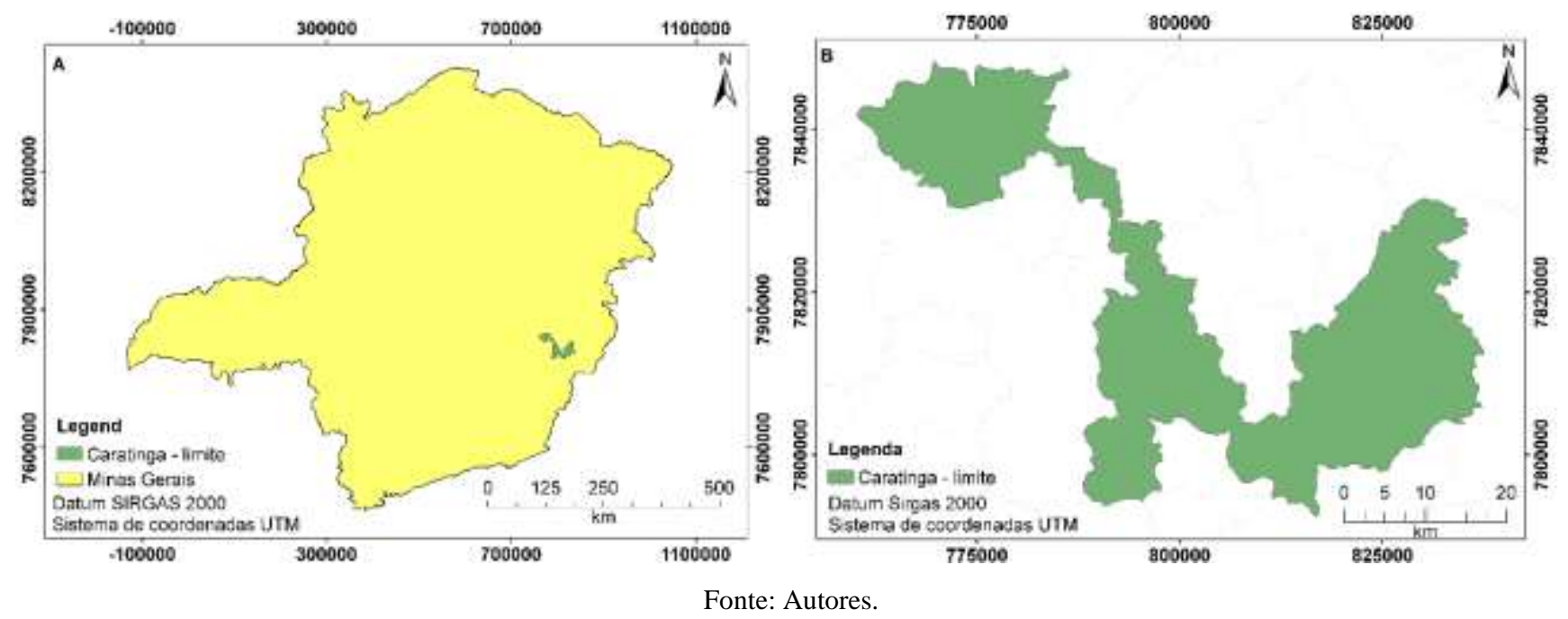

\subsection{Dados cartográficos}

Os dados cartográficos utilizados foram obtidos através dos órgãos responsáveis por cada parâmetro avaliado, dentre eles o Mapbiomas (dados de uso e cobertura do solo), Portal do Café de Minas (arquivo KML dos polígonos referentes as lavouras do município de estudo) e IDE-Sisema (dados do limite dos municípios de Minas Gerais, dados de solos de Minas Gerais, dados de rodovias estaduais e hidrografia de Minas Gerais). Foram adotadas restrições para cada tipo de dado com intuito de definir as áreas aptas ao cultivo do café arábica, visto que quase $100 \%$ das plantações no estado de Minas Gerais são dessa espécie (IBGE, 2019).

\subsection{Restrições para cursos hídricos}

De acordo com o capítulo II da Lei No 12.651, de 25 de maio de 2012, deve-se manter como Área de Preservação Permanente (APP) as faixas marginais de qualquer curso d'água natural perene e intermitente, variando de acordo com a largura do curso hídrico. Portanto, foi aplicado no modelo em estudo as faixas de APP de acordo com a largura de cada curso d'água, dados estes disponibilizados pelo IDE-Sisema. 


\subsection{Restrições para altitude}

A altitude adotada como de melhor aptidão seguiu as orientações de Mesquita (2016), no qual recomenda-se o plantio de café em áreas de altitude entre $600 \mathrm{~m}$ e $1.200 \mathrm{~m}$. Essa faixa altimétrica é a mais adequada devido à influência que exerce na longevidade, na produtividade da lavoura e na qualidade da bebida.

\subsection{Restrições para solos}

Com base nos dados de Guarçoni et al. (2019) e do Sistema Brasileiro de Classificação de Solos da Embrapa (2013), foi definido que os solos com maior aptidão para plantio de café são as classes latossolos e nitossolos. Esse tipo de solo foi considerado de maior aptidão devido a profundidade efetiva ser maior que a mínima de $120 \mathrm{~cm}$ sugerida e possuir boas condições de textura e estrutura (Mesquita et al. 2016).

\subsection{Restrições para rodovias}

Define-se como "Faixa de Domínio" a base física até o alinhamento das cercas que separam a estrada dos imóveis marginais ou da faixa do recuo (DNIT, 2019), amparada pela Lei $\mathrm{N}^{\circ}$ 6.766, de 19 de dezembro de 1979, que estabelece uma faixa não-edificável de $15 \mathrm{~m}$ de cada lado de rodovias e ferrovias. Portanto, foi adotado $15 \mathrm{~m}$ para ambos os lados das rodovias, uma vez que no município de Caratinga não possui ferrovias.

\subsection{Restrições para declividade}

De acordo com o SENAR, (2017) não é aconselhável o plantio de café em superfícies com declividade acima de 20\%, critério este adotado para o estudo. Para o preparo da declividade foi elaborado um mosaico através da junção de duas imagens da base de dados Shuttle Radar Topographic Mission (SRTM), e posteriormente executado o comando slope, cujas etapas são o input raster, output raster e output measurement, que no estudo foi aplicado o percent_rise, gerando um novo tema matricial. Com os dados obtidos através da ferramenta slope, foi possível aplicar a ferramenta raster calculator definindo o critério da declividade propícia ao cultivo do café.

\subsection{Restrições para áreas urbanas}

De acordo com a Instrução Normativa $N^{\circ} 2$ do MAPA (2008), a aplicação aeroagrícola é restrita a uma distância mínima de $500 \mathrm{~m}$ de povoações, cidades, vilas e bairros. Foi adotado uma distância mínima de $500 \mathrm{~m}$ de áreas urbanas. $\mathrm{Na}$ região em estudo não é comum o uso aéreo para aplicação de defensivos agrícolas, porém, o critério foi adotado por medida de segurança.

\subsection{Análise espacial}

Após as etapas de análises espaciais com suas respectivas restrições, foi utilizado o método multicritérios através da sobreposição ponderada de três camadas, sendo elas a declividade, altimetria e solos. Esse procedimento sobrepõe vários rasters usando uma escala de medição comum e ponderando cada um de acordo com a sua importância (ESRI, 2019). No entanto para o estudo, foi adotado a mesma importância para os três rasters, restringindo feições de acordo com os critérios adotados.

Após o arquivo gerado, foi aplicado o comando overlay erase com as três últimas restrições, sendo elas a APP, faixa de domínio das rodovias e limites das áreas urbanas. Esse procedimento consiste em cobrir o arquivo de entrada com os 
Research, Society and Development, v. 10, n. 4, e17410414050, 2021

(CC BY 4.0) | ISSN 2525-3409 | DOI: http://dx.doi.org/10.33448/rsd-v10i4.14050

polígonos do arquivo de exclusão. Somente as partes dos recursos de entrada que ficam fora dos recursos de exclusão são copiadas para a classe de recurso de saída (ESRI, 2019).

\section{Resultados e Discussão}

A rede de hidrografia do município de Caratinga com suas respectivas áreas de Preservação Permanente (APPs), somadas correspondem a 8,9\% da área do município (Figura 2).

Figura 2 - APPs referente a hidrografia do município de Caratinga.

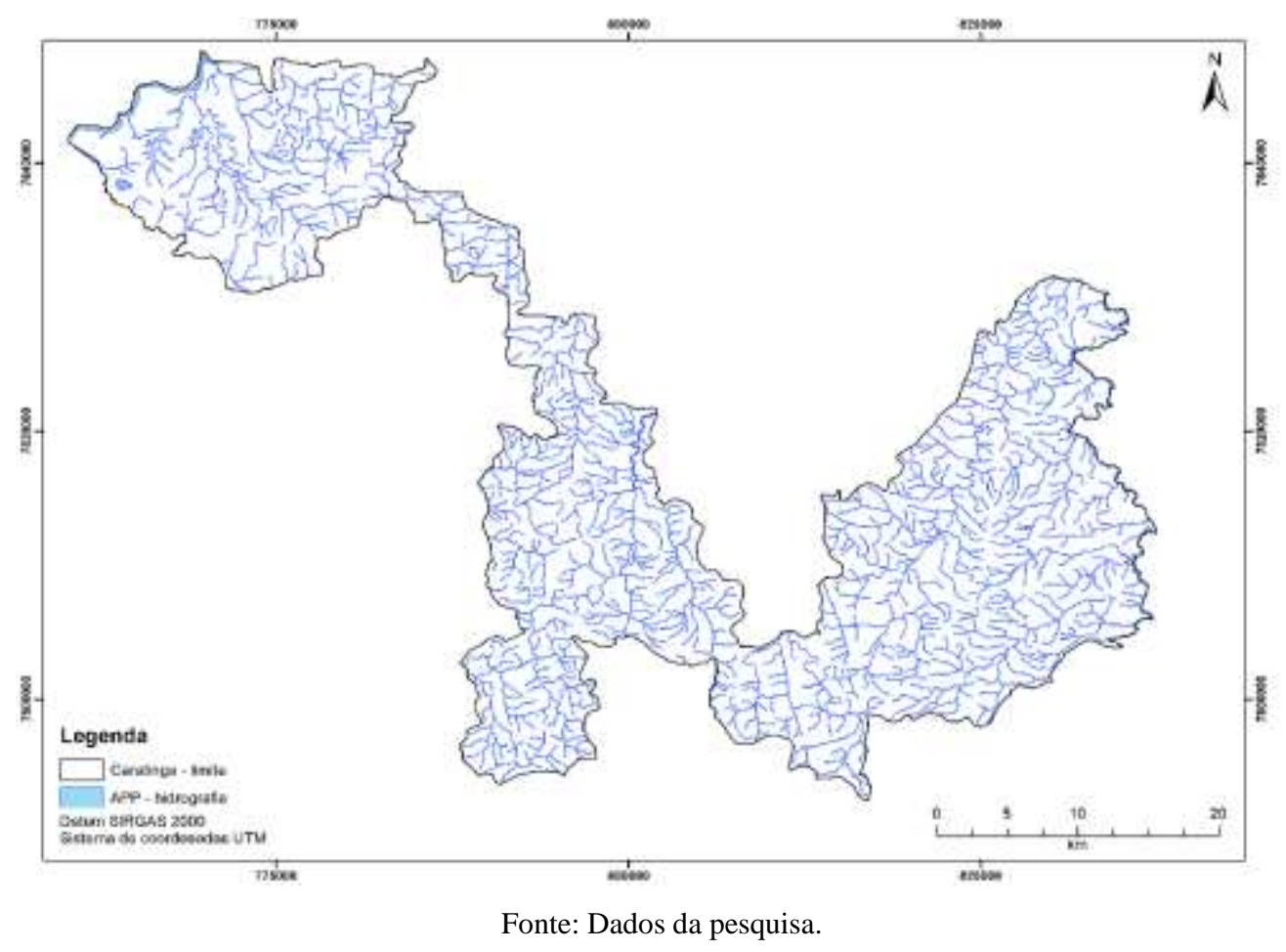

As altitudes entre $600 \mathrm{~m}$ e $1200 \mathrm{~m}$, correspondem a 53,3\% da área do município (Figura 3). De acordo com Mesquita et al. (2016) a altitude é um fator que influencia diretamente na produtividade do café, pois, oferece temperaturas mais baixas, maior precipitação associada ao sol forte, favorecendo o desenvolvimento do grão, acentuando o seu sabor, a sua acidez e seu aroma. 
Research, Society and Development, v. 10, n. 4, e17410414050, 2021

(CC BY 4.0) | ISSN 2525-3409 | DOI: http://dx.doi.org/10.33448/rsd-v10i4.14050

Figura 3 - Mapa reclassificado com as altitudes ideais para cultivo do café.

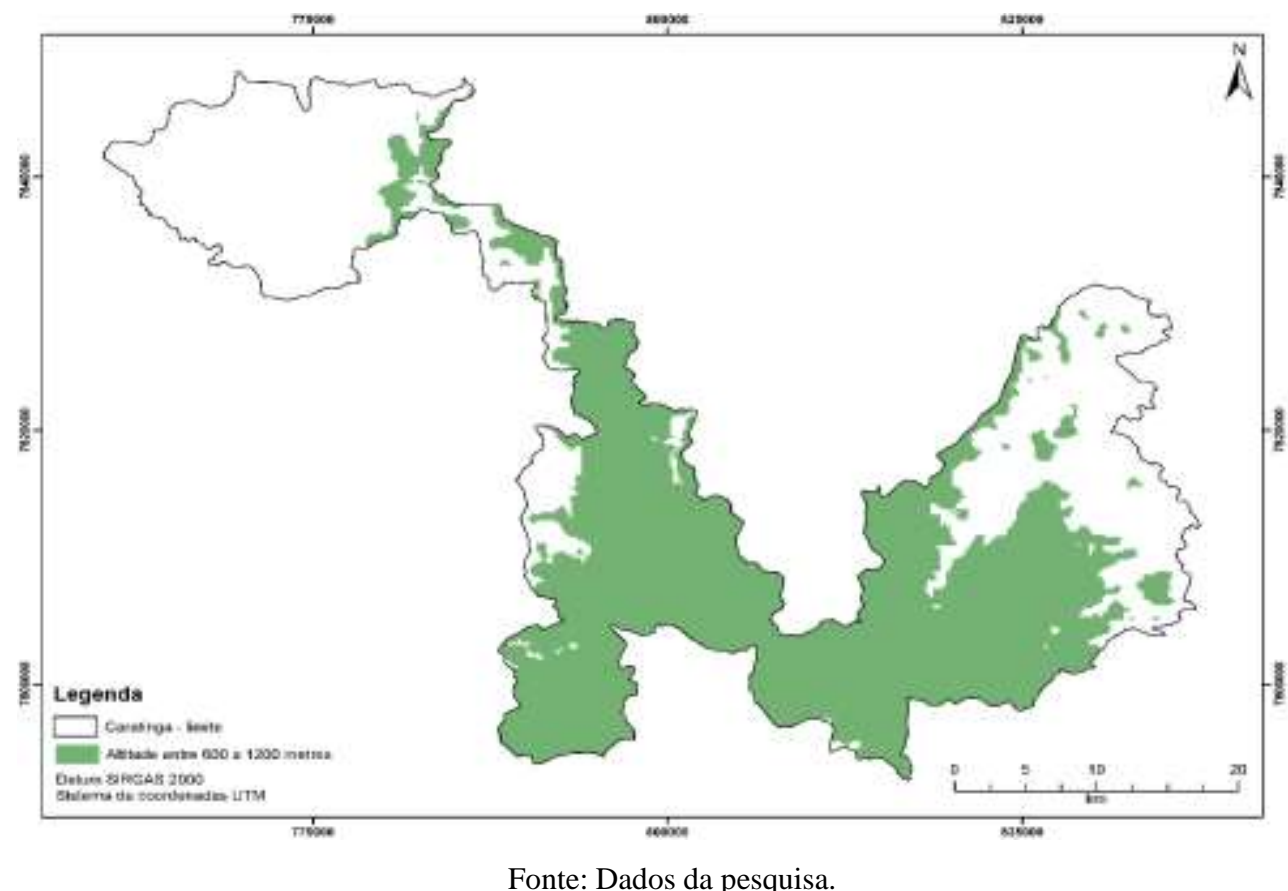

As classes de solos da área em estudo propicias ao cultivo de café abrangem 96\% do município (Figura 4). Foram encontradas as classes de Latossolos amarelo e Latossolos vermelho-amarelo, ambos com pequenas variações quanto a composição.

Figura 4 - Classes de solos favorável ao cultivo do café.

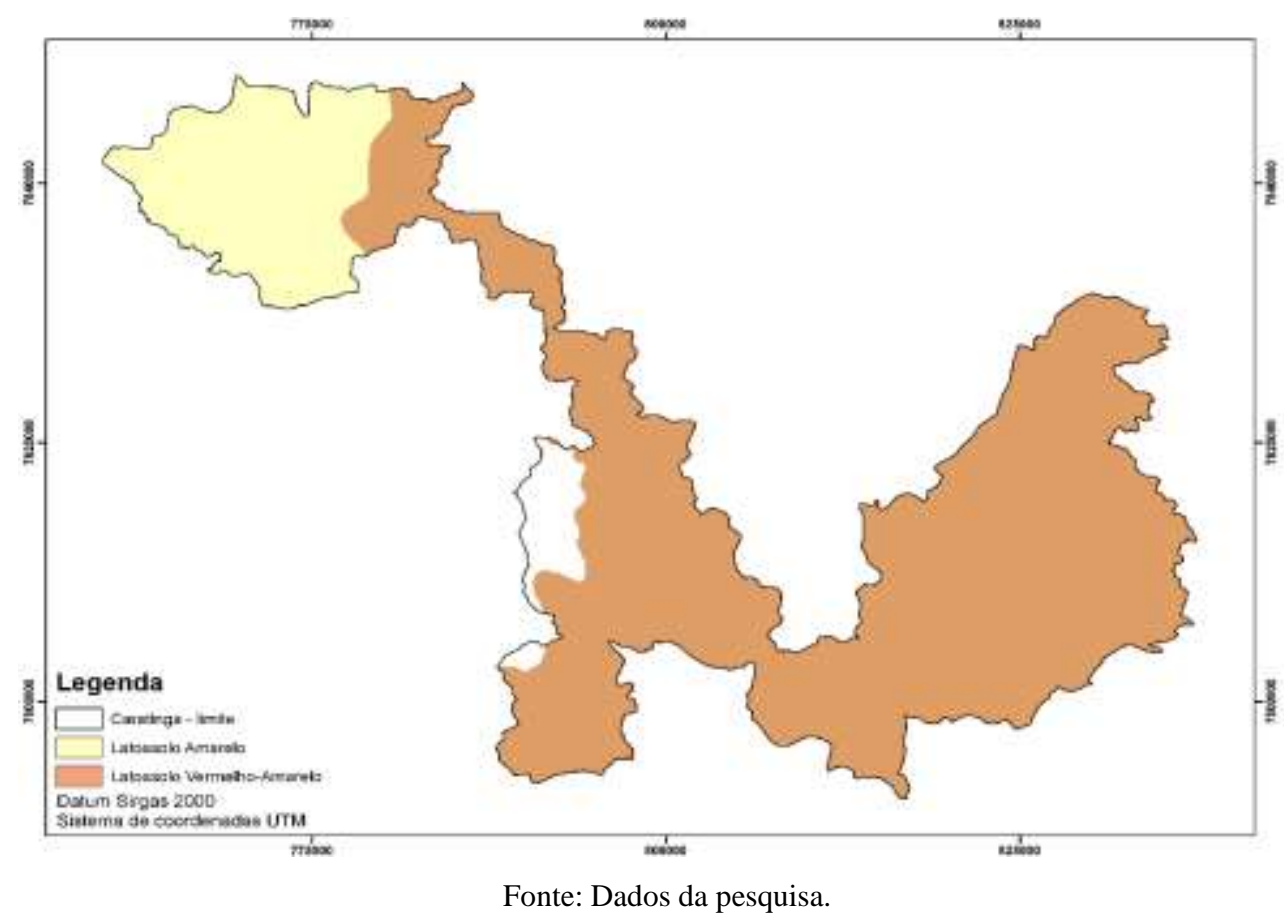

As faixas de domínio das rodovias no município de Caratinga, correspondem a 0,2\% da área do território (Figura 5). A principal rodovia no município é a BR-116 (Rodovia Rio-Bahia), por onde escoa boa parte dos produtos da região. 
Research, Society and Development, v. 10, n. 4, e17410414050, 2021

(CC BY 4.0) | ISSN 2525-3409 | DOI: http://dx.doi.org/10.33448/rsd-v10i4.14050

Figura 5 - Faixa de domínio das rodovias que cortam o município.

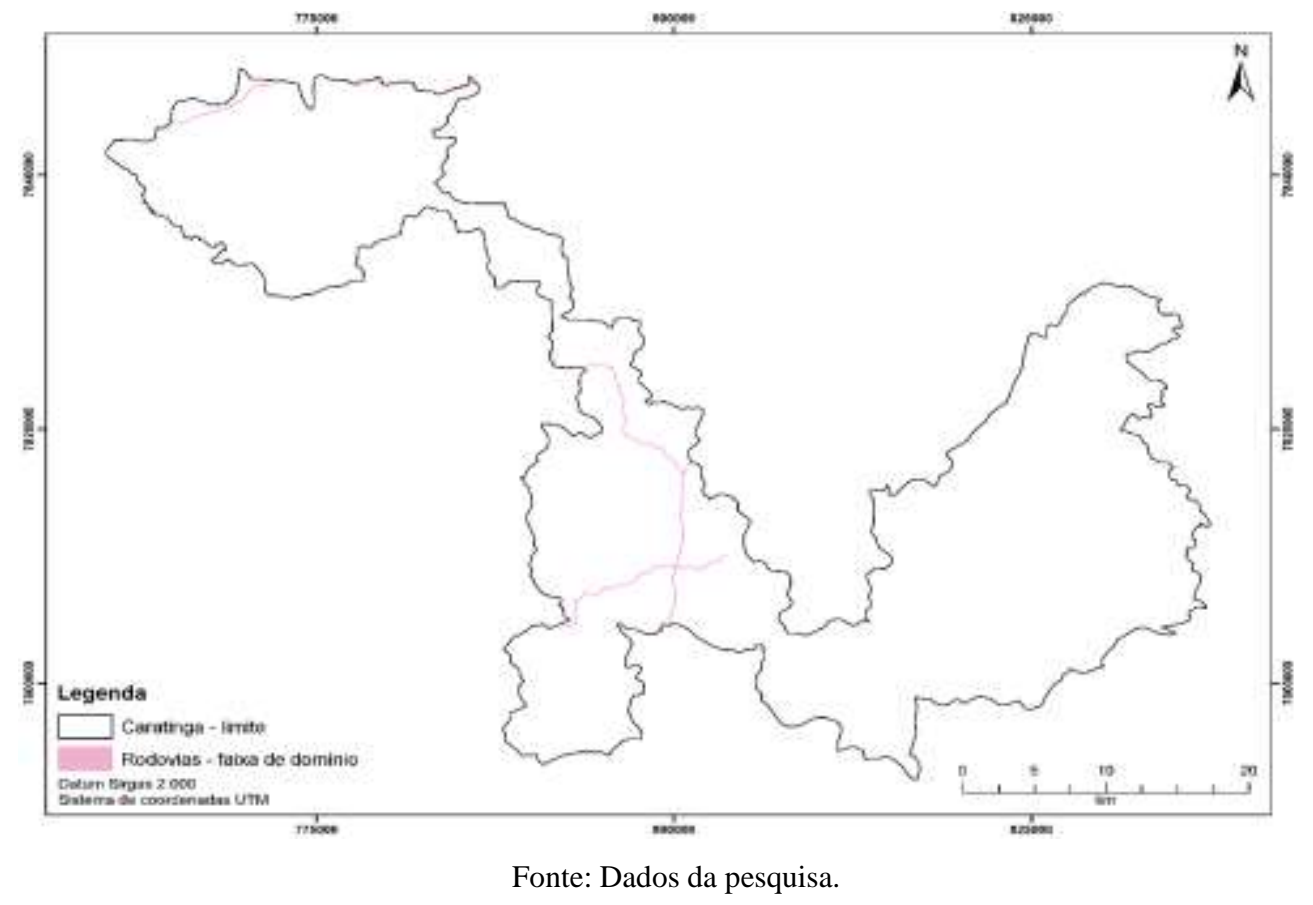

As áreas com declividades menores ou iguais a 20\%, correspondem a 83,4\% da área de estudo (Figura 6). Declividades acima de $20 \%$ limitam a mecanização da lavoura, dificulta o manejo, onera todo o processo desde a implantação a colheita do café (SENAR, 2017).

Figura 6 - Declividade favorável ao cultivo de café no município de Caratinga.

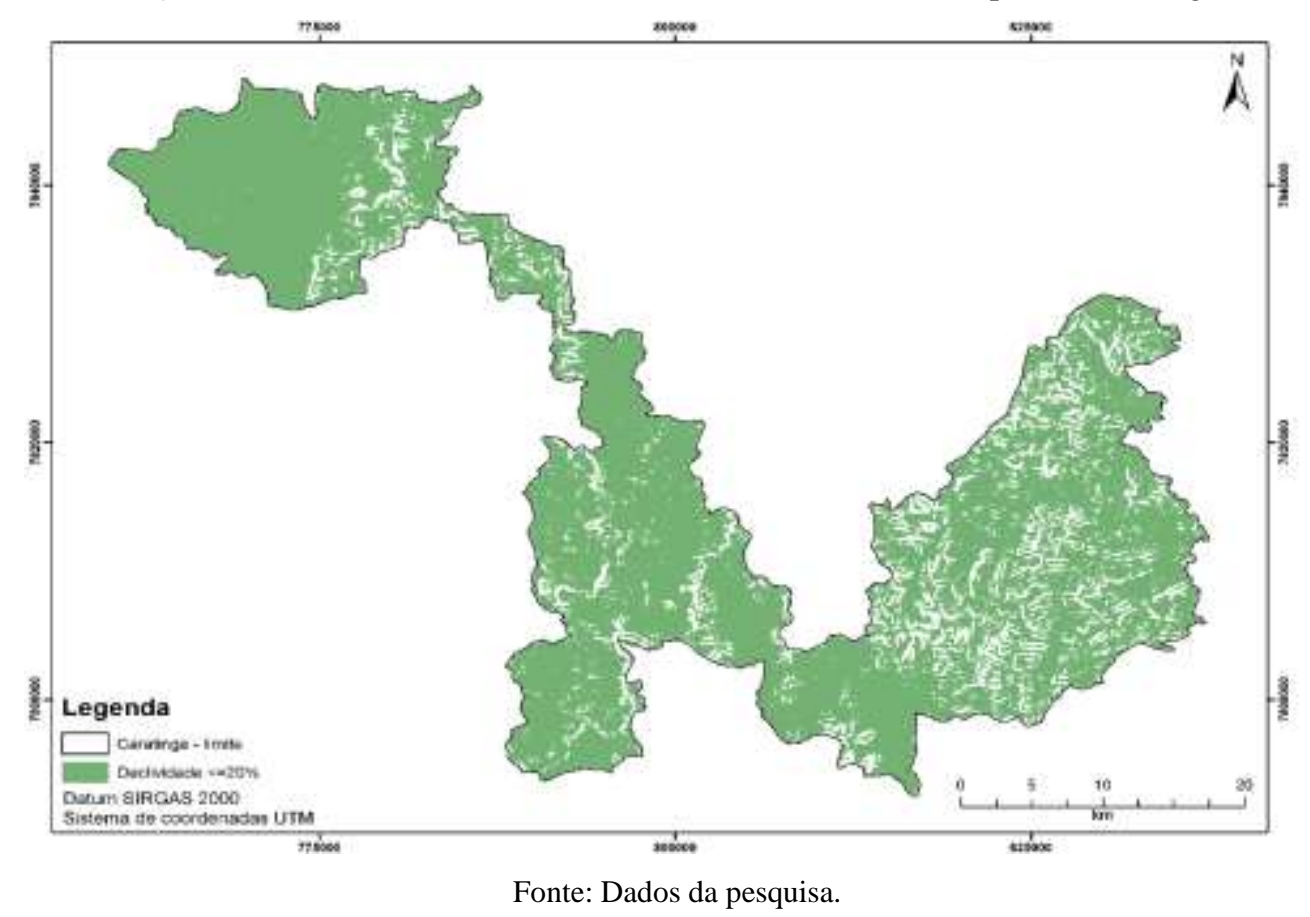

Após a aplicação da restrição proposta, as áreas urbanas correspondem a 1,9\% do território (Figura 7). 
Figura 7 - Limites de restrições das áreas urbanas.

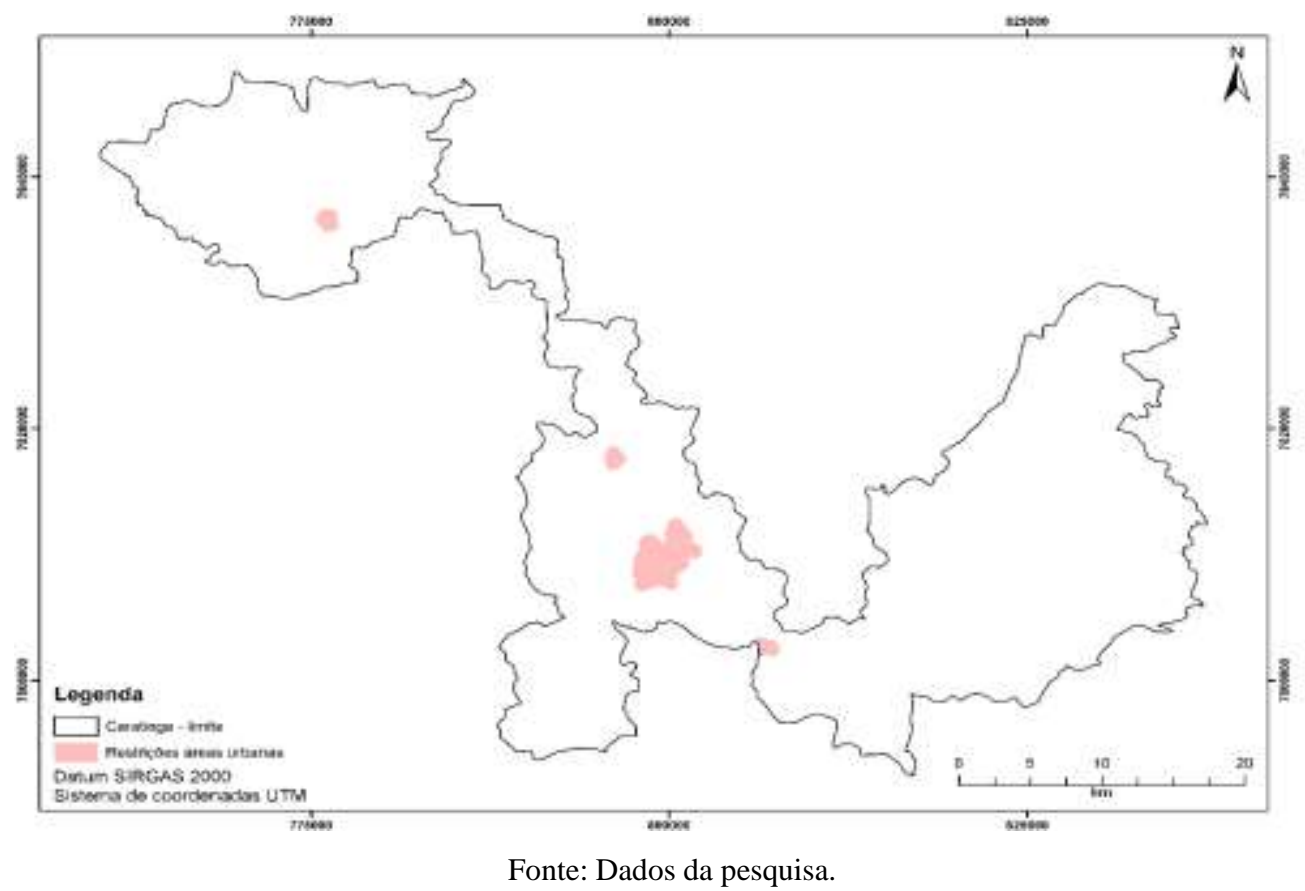

As áreas favoráveis ao cultivo do café após aplicado os critérios estabelecidos possuem 48.212 ha, caracterizando $38,3 \%$ do território de Caratinga (Figura 8).

Figura 8 - Mapa das áreas adequadas para o cultivo do café (Coffea Arabica L.) no município de Caratinga.

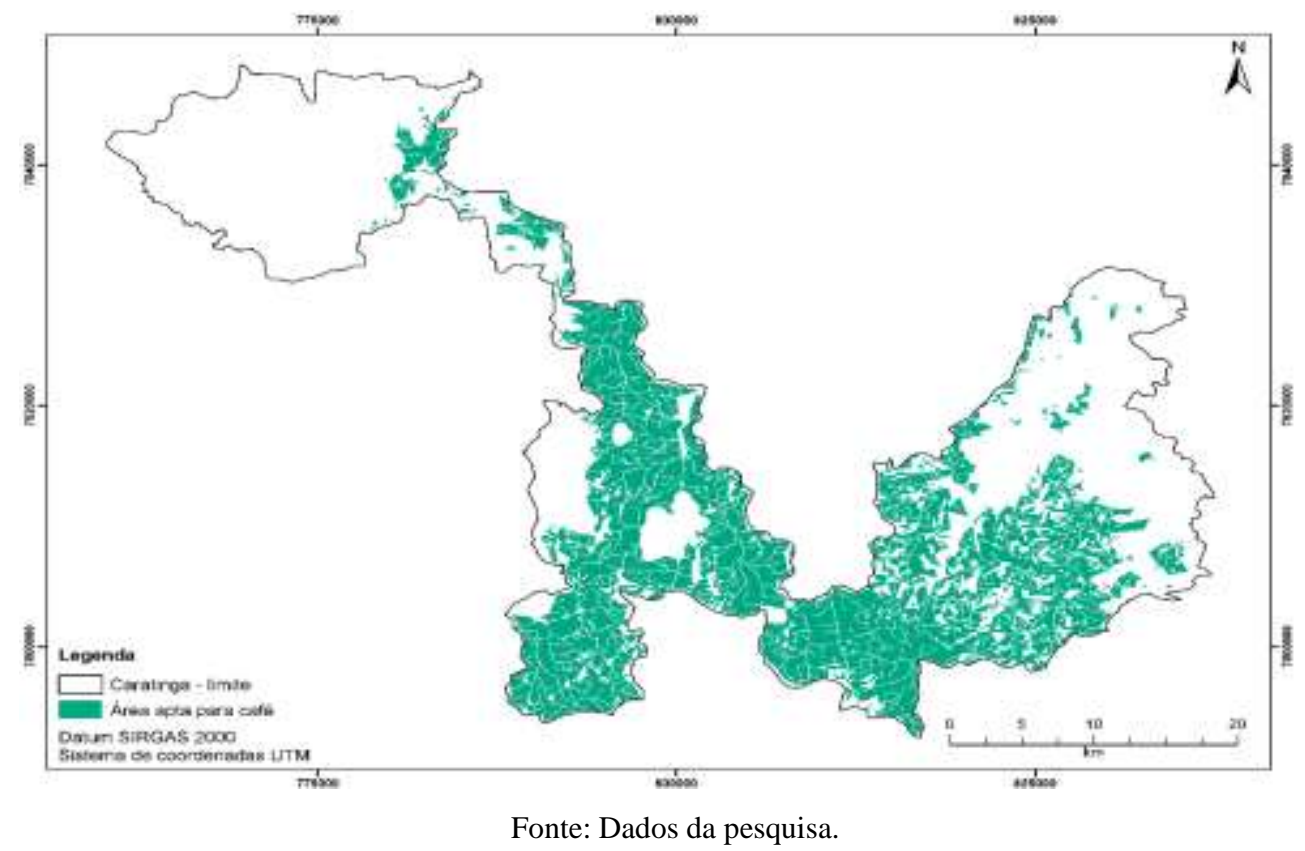

Através dos dados de lavouras de café fornecidos pelo Projeto observatório da agricultura de Minas Gerais (Portal do café de minas, 2018), foi possível compará-lo com os dados das áreas aptas para café do município em estudo. Através do procedimento proporcionado pelo uso da ferramenta overlay erase, foi possível avaliar e quantificar as áreas aptas para plantio de café e que atualmente possuem ou não lavouras (Figura 9), constatando que dos 12.342 hectares da cultura existente em 
Caratinga, aproximadamente 88,6\% concentra-se na área estabelecida pelo estudo como apta ao cultivo do café. Esse valor obtido indica a qualidade do estudo, mostrando que a análise espacial é capaz de detectar áreas potenciais ao cultivo do grão, contribuindo com informações que ajudam nas tomadas de decisões. As lavouras localizadas fora das áreas delimitadas como aptas podem ser decorrentes dos critérios estabelecidos, uma vez que na região há lavouras de pequenos produtores, no qual os tratos culturais e as colheitas são manuais, justificando serem implantadas em inclinações superiores a $20 \%$.

Figura 9 - Lavouras de café implantadas no município de Caratinga.

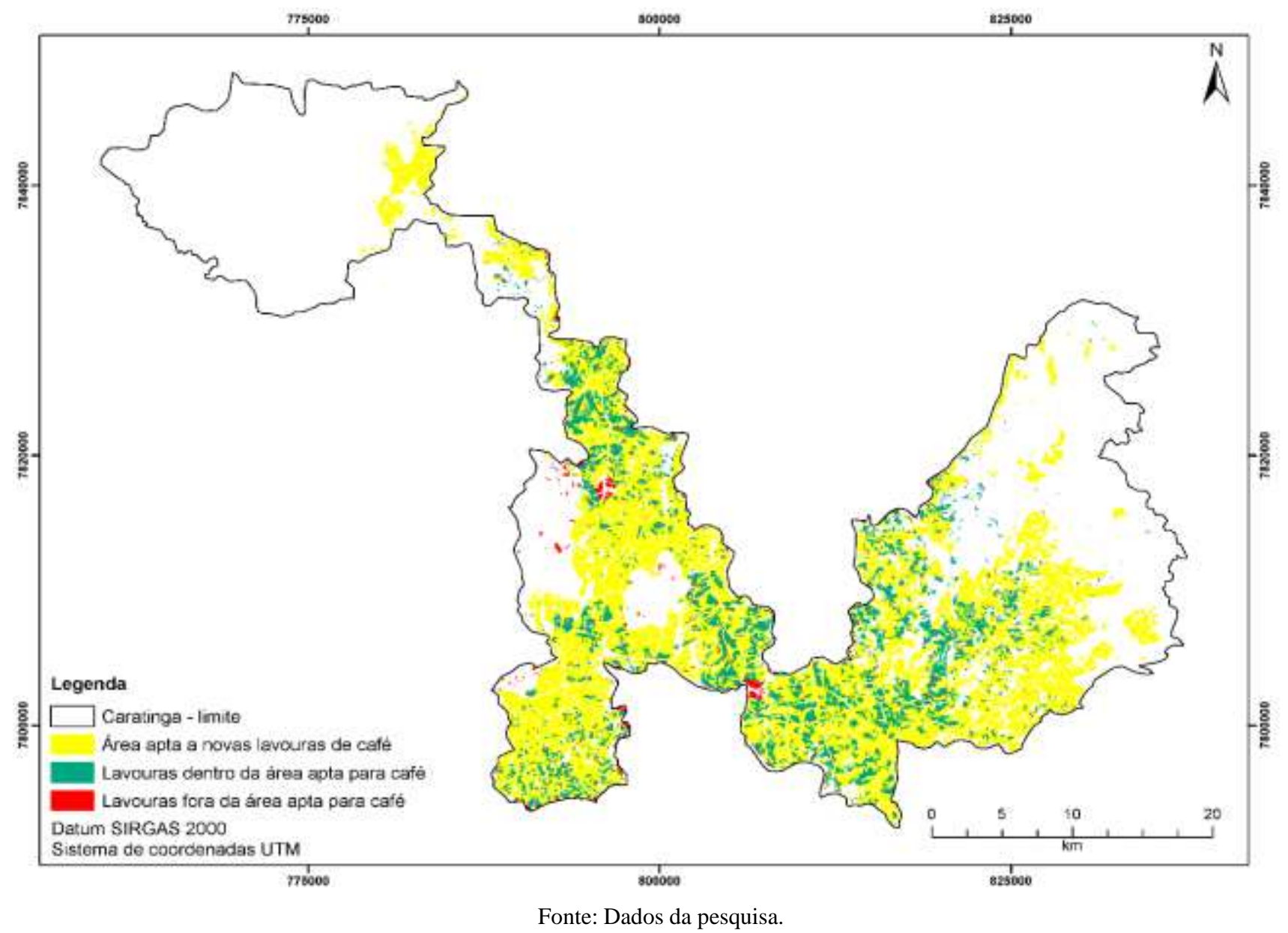

O “Zoneamento Agrícola para a cultura de café no Estado de Minas Gerais” do MAPA (2011), aponta o município de Caratinga como apto ao cultivo de café arábica no sequeiro, e apto ao cultivo do café robusta no sequeiro ou irrigado de acordo com seus critérios. Os resultados obtidos estão de acordo com o zoneamento para a cultura do café, corroborando ao valor obtido de áreas aptas no município.

Bernardes et al. (2012) analisaram a cafeicultura no estado de Minas Gerais, com o uso de técnicas de geoprocessamento e constataram que as lavouras no estado ocorrem em todas as classes de declividade, sendo que no geral, a maioria são implantadas em declividades inferiores a 20\%. Esses resultados são condizentes aos constatados no presente trabalho.

O uso do geoprocessamento no estudo da cultura cafeeira tem proporcionado informações importantes para a agricultura. Peluzio et al. (2020) mapearam a distribuição das lavouras de café no território do Caparaó Capixaba, proporcionando um diagnóstico da contribuição dos municípios com a cultura no estado. Moreira et al. (2010) identificaram e 
mapearam áreas de café cultivadas nos estados de Minas Gerais e São Paulo. Através de imagens de satélites elaboraram estatísticas agrícolas referente a cultura para os dois estados, possibilitando uma visão da distribuição das lavouras em cada mesorregião.

O geoprocessamento é uma ferramenta com grandes potencialidades, podendo ser aplicada no mapeamento da aptidão e potencial de uso agrícola dos solos, levantamento de propriedades rurais, controle na ação de abastecimento de água, exploração seletiva e sustentável dos produtos florestais existentes, dentre outros, possibilitando ganhos significativos ao produtor do campo (Matsushita, 2014; Ferreira et al., 2018).

\section{Conclusão}

O município de Caratinga possui $9,8 \%$ do seu território com a cultura cafeeira e dispõe de áreas com potencialidade para implantação de novas lavouras de café, em torno de $28,7 \%$ do território se mostra apto ao cultivo do grão de acordo com critérios estabelecidos.

Este trabalho possibilitou a análise, interpretação e quantificação de áreas aptas ao cultivo do café arábica, evidenciando a importância e agilidade do geoprocessamento como ferramenta de apoio para tomadas de decisões no meio rural.

O uso das geotecnologias no meio agrícola fornece informações qualitativas e quantitativas, promovendo um planejamento mensurável referente ao objetivo desejado, seja de caráter exploratório, informativo ou gerencial.

Os conhecimentos obtidos através deste trabalho podem ser aprimorados em trabalhos futuros, usando métodos de ponderação de parâmetros, como o método Analytic Hierarchy Process (AHP), para identificação de classes com a aptidão a implantação da cultura do café.

\section{Referências}

Ângelo, A. R., Passos, E. \& Moarais, J. L. (2017). Geoprocessamento aplicado à determinação da aptidão agrícola de terras: localidade de Serrinha, Paiçandu, estado do Paraná, Brasil. Ambiência Guarapuava, 13, 158-175.

Barros, A. C., Tagliarini, F. S. N., Garcia, Y. M., Minhoni, R. T. A., Barros, Z. X. \& Zimback, C. R. L. (2019). Mapeamento da aptidão agrícola das terras por meio de análise multicritério. Revista de Ciências Agrárias, 42(2), 295-304.

Bernardes, T., Moreira, M. A., Adami, M. \& Rudorff, B. F. T. (2012). Diagnóstico físico-ambiental da cafeicultura no estado de Minas Gerais - Brasil. Coffee Science, 7 (2), 139-151.

Cobra, R. L., Silva, R. C., Oliveira, G. F. A., Miranda, D. L., Leonardi, F. A. \& Silva, M. L. (2019). Geoprocessamento aplicado ao levantamento e avaliação de solos: Proposta de avaliação de terras para fins agrícolas no Município de Inconfidentes - MG. Revista Brasileira de Geografia Física, 12 (2), $397-411$.

Companhia Nacional de Abastecimento (2020). Acompanhamento da safra brasileira de café. 5(6), quarto levantamento. Brasília, CONAB.

Departamento Nacional de Infraestrutura de Transportes (2019). Faixa de domínio. http://www.dnit.gov.br/rodovias/operacoes-rodoviarias/faixa-de-dominio.

ESRI. Desktop, 10.6.1.

Ferreira, G. R., Ferreira, W. P. M., Barbosa, T. K. M., Luppi, A. S. L. \& Silva, M. A. V. (2018). Thermal zoning for mountain coffee crops in the Matas de Minas region, Brazil. Revista Brasileira de Geografia Física, 11 (4), 1176-1185.

Guarçoni, A., Souza, G. S. \& Sá Paye, H. (2019). Representatividade da amostra de solo de acordo com o volume coletado em lavoura de café Arábica. Colloquium Agrariae, 15 (3), 69-78.

Instituto Brasileiro de Geografia e Estatística (2019). Produção Agrícola Municipal ano base 2019. https://sidra.ibge.gov.br/tabela/1613. Acesso em: 10 fev 2021.

Instituto Brasileiro de Geografia e Estatística (2020). Brasil / Minas Gerais / Caratinga. https://cidades.ibge.gov.br/brasil/mg/caratinga/panorama.

Instituto Nacional de Meteorologia (2020). Estações convencionais. http://www.inmet.gov.br/portal/index.php?r=home/page\&page=rede_estacoes_conv_graf.

Lei n 12.651 (2012). Dispõe sobre a proteção da vegetação nativa. Brasília, Diário Oficial da União. 
Research, Society and Development, v. 10, n. 4, e17410414050, 2021

(CC BY 4.0) | ISSN 2525-3409 | DOI: http://dx.doi.org/10.33448/rsd-v10i4.14050

Lei n 6.766 (1979). Dispõe sobre o Parcelamento do Solo Urbano e dá outras Providências. Brasília, Diário Oficial da União.

Matsushita, M. S. (2014). Trabalhos da Extensão Rural com uso de Geoprocessamento. Instituto Emater.

Mesquita, C. M. Et al. (2016). Manual do café: implantação de cafezais Coffea arábica L. EMATER.

Ministério da Agricultura, Pecuária e Abastecimento (2011). Portaria 80/2011, Secretaria de política agrícola - MAPA. http://sistemasweb.agricultura.gov.br/sislegis/action/detalhaAto.do?method=visualizarAtoPortalMapa\&chave =627565700.

Ministério da Agricultura, Pecuária e Abastecimento (2018). Café no Brasil. http://www.agricultura.gov.br/assuntos/politica-agricola/cafe/cafeiculturabrasileira.

Moreira, M. A., Rudorff, B. F. T., Barros, M. A., Faria, V. G. C. \& Adami, M. (2010). Geotecnologias para mapear lavouras de café nos estados de Minas Gerais e São Paulo. Engenharia Agrícola, 30 (6), 1123-1135.

Nasser, M. D., Tarsitano, M. A. A., Lacerda, M. D. \& Koga, P.S.L. (2012). Análise econômica da produção de café arábica em são Sebastião do Paraíso, estado de Minas Gerais. Informações Econômicas, 42 (2), 5-12.

Peluzio, T. M. O., Sturião, A. P., Peluzio, J. B. E., Ferrari, J. L. \& Jaeggi, M. E. P. C. (2020). Uso da geotecnologia para o mapeamento da cafeicultura no Caparaó Capixaba. Revista Ifes Ciência, 6 (4), 92-104

Portal do Café de Minas (2018). Projeto Observatório da Agricultura de Minas Gerais. http://portaldocafedeminas.emater.mg.gov.br/\#inicio.

Rosa, V. G. C., Moreira, M. A., Rudorff, B. F. T. \& Adami, M. (2010). Estimativa da produtividade de café com base em um modelo agrometeorológico-espectral. Pesquisa Agropecuária brasileira, 45 (12), 1478-1488.

Serviço Nacional de Aprendizagem Rural (2017). Café: formação da lavoura/ Serviço Nacional de Aprendizagem Rural. SENAR.

Silva, F. M. \& Medeiros, P. S. M. (2020). Impacto da cafeicultura no uso e ocupação do solo da bacia do rio Ribeirão Cacau-RO. Ciência Geográfica, XXIV (2), 619-634.

Ximenes, L. J. F. \& Vidal, M. F. (2017). Produtor de café no Brasil: mais agro e menos negócio. Caderno Setorial ETENE, 2 (12), 1-15. 